\title{
FURTHER STUDIES OF THREE ANTI-EMETICS IN COMMON USE
}

\author{
Richard G. B. TAN, DRS. MED. (AIRLANGGa), LARRY J. Gelmon, aND \\ GoRDON M. WYANT, F.F.A.R.C.S., F.A.C.P.(c)*
}

IN 1962 we published our findings of the anti-emetic effects of trimethoxybenzamide (Tigan ${ }^{\oplus}$ ) in dogs as part of a comparative study of eleven such agents. ${ }^{1}$ At that time we showed that in doses of $4.55 \mathrm{mg}$. $/ \mathrm{kg}$., trimethoxybenzamide afforded an average protection of 90 per cent against an apomorphine challenge of $0.06 \mathrm{mg} . \mathrm{kg}$. Thus trimethoxybenzamide compared favourably with the protection afforded by chlorpromazine, trifluoperazine, levomepromazine, proclorperazine, perphenazine, and thiethylperazine. For some of these agents, however, the equivalent protection dose for man in terms of milligrammes per kilogramme body weight would have been associated with considerable sideeffects, whereas that for trimethoxybenzamide fell well within the human therapeutic range.

Because of these favourable results we were the more surprised at the subsequent findings of Purkis ${ }^{2}$ which showed that trimethoxybenzamide was the most ineffectual anti-emetic tested in his series in man. These conclusions could not be reconciled with our laboratory findings. Since it was difficult to conceive of these discrepancies as the result of species differences alone, the answer would have to lie, at least in part, with the conditions under which observations were made. Two basic differences are obvious. First, the total amount of trimethoxybenzamide used by Purkis was considerably higher by comparison than that used by us, suggesting the possibility of a drug reversal effect due to exceptionally large doses of the agent. Secondly, his direct observations of each patient extended over a two-hour period with additional evaluation from ward records embracing a total span of 48 hours, whereas our experiments in dogs only noted presence or absence of protection in the face of one acute challenge.

The following experiments were conducted to confirm or refute the validity of these two factors. $千$

\section{STUDY}

The actual study was conducted in two parts. The first was designed to test the hypothesis of a reversal effect and the second to investigate the time element. The experimental set-up was that employed in our previous study, at least as far as apomorphine was concerned.

\section{Part A}

Ten mongrel dogs were used which had been maintained on standard dog

"From the Department of Anaesthesia, University of Saskatchewan, and University Hospital, Saskatoon, Saskatchewan. Dr. Tan was a Research Fellow and Mr. Gelmon a summer student in the Department of Anaesthesia and as such carried out work on Parts A and B respectively. tThe authors are indebted to Dr. Purkis for suggesting that they investigate the time factor. 
food pellets, one daily meal of meat and water ad lib. The minimum emetic dose of apomorphine following a standard meat meal 15 minutes previously for this group of animals was found to be $0.05 \mathrm{mg} . / \mathrm{kg}$. intramuscularly, a figure not too dissimilar from that obtained in our previous study. For the actual experiments, the same meat meal was given 10 to 15 minutes prior to the intramuscular administration of a preselected dose of trimethoxybenzamide. This was followed 10 to 20 minutes later by the apomorphine challenge. Three series of experiments were conducted. Series A consisted of $3 \mathrm{mg} . / \mathrm{kg}$. trimethoxybenzamide, designed to reproduce our previously reported experiments, compensating for the slightly lesser apomorphine challenge by reduction of the amount of trimethoxybenzamide. In Series B, $6 \mathrm{mg} . / \mathrm{kg}$. trimethoxybenzamide was used, and in Series C, $12 \mathrm{mg} . / \mathrm{kg}$, exceeding even the dose used by Purkis in his study. At least two days were allowed to elapse between individual experiments.

\section{Part B}

Again ten mongrel dogs, but different from those of Part A, were used. In addition to trimethoxybenzamide, thiethylperazine (Torecan ${ }^{(1)}$ ) and perphenazine (Trilafon ${ }^{8}$ ) were tested, since these were the three anti-emetics compared by Purkis in his study. It was again ascertained in control experiments that apomorphine $0.05 \mathrm{mg} . / \mathrm{kg}$. intramuscularly consistently made all dogs vomit, and it was furthermore noted that this occurred within five to six minutes of the time of injection. All animals were submitted to all three anti-emetics under study in random sequence at alternate days. The agent to be studied was injected first and the apomorphine challenge was administered at half-hour, one hour, two hours, and four hours following protection. If at any time protection was no longer evident, further challenges were omitted. The interval elapsing between the administration of the apomorphine challenge and the occurrence of actual vomiting was noted and was related to a control period of six minutes.

\section{Results}

The results of Part A are evident from Figure 1. Series A clearly reproduces the findings of our previous study, in that 90 per cent protection was again obtained. This would seem to confirm that our previous results were not fortuitous. By doubling the protective dose (Series B) no changes could be produced either for the better or for the worse. Four times the original dose of trimethoxybenzamide (Series C) increased the protection rate to 100 per cent which would clearly exclude any reversal properties of the agent even in very high doses.

The results of Part B are listed in Table I.

Trimethoxybenzamide. Trimethoxybenzamide was effective against an apomorphine challenge after half an hour within the standard six minutes in nine out of ten dogs (90\%). In two of the remaining nine the protection was relative in that emesis did occur although belatedly (dogs nos. 3 and 10). None of the dogs remained protected from the next challenge half an hour later, although in five of them the response to apomorphine was delayed, and this markedly so in dog no. 8. 


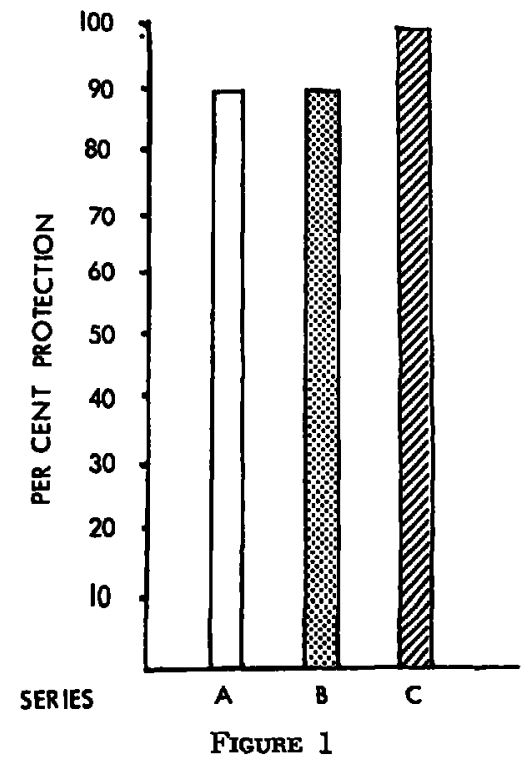

TABLE I

Anti-Emetics Tested

\begin{tabular}{|c|c|c|c|c|c|c|c|c|c|c|c|c|}
\hline \multirow{2}{*}{$\begin{array}{l}\text { Dog } \\
\text { No. }\end{array}$} & \multicolumn{4}{|c|}{ Trimethoxybenzamide } & \multicolumn{4}{|c|}{ Thiethylperazine } & \multicolumn{4}{|c|}{ Perphenazine } \\
\hline & $\mathrm{hr}$. & $1 \mathrm{hr}$. & $2 \mathrm{hr}$. & $4 \mathrm{hr}$. & $\frac{1}{2} \mathrm{hr}$. & $1 \mathrm{hr}$. & 2 hr. & $4 \mathrm{hr}$. & $\frac{1}{2} \mathrm{hr}$. & $1 \mathrm{hr}$. & $2 \mathrm{hr}$. & $4 \mathrm{hr}$. \\
\hline 1 & & $x^{0}$ & & & & & $x^{5}$ & & & & & $\rightarrow$ \\
\hline 2 & & $x^{9}$ & & & & & & $x^{6}$ & & & & $\rightarrow$ \\
\hline 3 & $x^{10}$ & & & & & $x^{5}$ & & & & $x^{0}$ & & \\
\hline $\begin{array}{l}\mathbf{4} \\
\mathbf{5}\end{array}$ & & $\begin{array}{l}X^{8} \\
X^{5}\end{array}$ & & & & $\begin{array}{l}X^{16} \\
X^{8}\end{array}$ & & & $x^{5}$ & & & $x^{4}$ \\
\hline 6 & $x^{6}$ & & & & $x^{7}$ & & & & & & & $\rightarrow$ \\
\hline $\begin{array}{l}7 \\
8\end{array}$ & & $\begin{array}{l}X^{5} \\
X^{28}\end{array}$ & & ? & & & $x^{10}$ & $x^{5}$ & $x^{5}$ & & & $\rightarrow$ \\
\hline 9 & & $x^{0}$ & & & & & & $\rightarrow$ & $x^{6}$ & & & \\
\hline 10 & $x^{12}$ & & & & & & & $\rightarrow$ & & $x^{5}$ & & \\
\hline
\end{tabular}

$X$ indicates emesis after an apomorphine challenge of $0.05 \mathrm{mg} . / \mathrm{kg}$. The number against each $X$ denotes the time in minutes at which emesis occurred following the administration of apomorphine. An arrow indicates any cases in which protection was still complete at the four-hour challenge. Protection doses were: trimethoxybenzamide, $3.0 \mathrm{mg}$. $/ \mathrm{kg}$.; thiethylperazine, $0.1 \mathrm{mg} . / \mathrm{kg}$.; perphenazine, $0.02 \mathrm{mg} . / \mathrm{kg}$.

Thiethylperazine. None of the animals vomited within six minutes of the administration of apomorphine, but since one dog vomited as little as one minute later, it is fair to say that a 90 per cent protection was obtained. The next challenge at one hour failed to protect a further three animals, although in one (dog no. 4) partial protection was present, vomiting being delayed for sixteen minutes. Of the remaining six dogs, two had lost protection to the administration of the two-hour challenge, and another two had done so after four hours. Two dogs remained protected beyond the four-hour observation period. 
Perphenazine. Only 70 per cent of the dogs were protected by the dose of $0.02 \mathrm{mg} . \mathrm{kg}$. Of the remaining seven animals, two more bad lost protection to the one-hour stimulus, but the others remained protected for a total period of four hours and beyond.

\section{Discussion}

These studies again emphasize the efficacy of trimethoxybenzamide as an antiemetic against apomorphine-induced vomiting in dogs and the absence of any side-effects even if unrealistically high doses are employed. There is no evidence of a reversal effect in the presence of these large doses.

The study bears out the suggestion by Purkis that the reason for the discrepancies between his and our original study are to be found in the time factor. All three agents tested are effective anti-emetics to a single stimulus, but the protection afforded by trimethoxybenzamide only extends over a period of less than 60 minutes. On the other hand, thiethylperazine still affords 60 per cent protection after one hour, and indeed 20 per cent of the animals were protected beyond the four hours of our observation period. Perphenazine lost its protective effect in $\mathbf{5 0}$ per cent of all animals within one hour, and in this it is not too dissimilar from thiethylperazine, but with one exception all dogs which were still protected at that time also remained so beyond the four-hour period. It is reasonable to assume that the percentage of dogs protected beyond the four-hour period would have been even greater had a 90 per cent initial protection been achieved by a slightly greater dose of perphenazine.

From this study it would seem, therefore, that while there is little to distinguish the three agents when they are used for short-range protection, thiethylperazine or perphenazine are preferable to trimethoxybenzamide if later resumption of vomiting is to be prevented in patients. Those animals which remained protected for one hour could expect to remain so, for a further two hours at least, more consistently after perphenazine than if they had received thiethylperazine.

\section{SUMMARY}

This study was undertaken in an attempt to resolve the contradictions between our previous findings in dogs regarding the anti-emetic properties of trimethoxybenzamide and the findings of Purkis regarding its properties in man.

From these further investigations it is clear that a reversal effect does not occur when large doses of trimethoxybenzamide are administered. The discrepancies are rather due to the fact that the therapeutic effect of trimethoxybenzamide is very short, whereas the effect of thiethylperazine and perphenazine is much more prolonged.

The difference between our original results and Purkis's can now be explained on the basis of the more prolonged observation of patients carried out by Purkis, as opposed to our acute experiments in dogs, when only the presence or absence of protection to a single stimulus was recorded. 


\section{RÉSUMÉ}

Nous avons entrepris cette étude pour essayer de résoudre les contradictions entre nos résultats antérieurs chez le chien concernant les propriétés antiémétiques du trimethoxybenzamide et ceux que le docteur Purkis a obtenu chez l'homme.

A la suite de ces dernières recherches, il nous semble évident qu'il ne survient pas d'effet renversé lorsque nous administrons de fortes doses de trimethoxybenzamide. Il serait plausible que les différences soient attribuables plutôt au fait que l'effet thérapeutique du trimethoxybenzamide est court alors que celui du thiéthylperazine et de la perphenazine est beaucoup plus long.

La différence des résultats entre les observations de Purkis et les nôtres peuvent s'expliquer sur la base d'une observation plus longue sur les malades de Purkis. en comparaison avec une expérience rapide sur nos chiens alors que nous tenions compte seulement de la présence ou de l'absence de protection à un seul stimulus.

\section{REFERENCES}

1. Wyant, Gombon M. A Comparative Study of Eleven Anti-Emetic Drugs in Dogs. Canad. Anaesth. Soc. J. 9: 399 (1962).

2. Purkas, IAN E. The Action of Thiethylperazine (Torecan 19 ), a New Anti-Emetic, Compared with Perphenazine (Trilafon ${ }^{(1)}$ ), Trimethoxybenzamide (Tigan(1), and a Placebo. in the Suppression of Postanaesthetic Nausea and Vomiting. Canad. Anaesth. Soc. J12: 595 (1965). 